\title{
MODERNIDAD Y CONOCIMIENTO SOCIAL. LA EMERGENCIA DE UN DISCURSO EPISTÉMICO EN AMÉRICA LATINA
}

\author{
Julio Mejía Navarrete
}

\section{RESUMEN}

Desde fines del siglo XV la mundialización del saber europeo comporta la supremacía de la razón que confluye en una unidad con dominación y la modernidad con colonialidad. Sin embargo, en América Latina siempre se han desarrollado momentos de respuesta epistémica frente al proceso de universalización del saber moderno y colonial. Los orígenes de un pensamiento alternativo se encuentran en las mismas raíces de la colonización de América. Así en América Latina se abre un momento de discusión y crítica, se ensayan una pluralidad de perspectivas que conllevan el desarrollo de propuestas que se distancian del discurso eurocéntrico.

Palabras CLAVE: Modernidad, conocimiento social, discurso epistémico, América Latina.

\section{MODERNITY AND SOCIAL KNOWLEDGE. THE EMERGENCY EPISTEMIC A SPEECH IN LATIN AMERICA}

\section{ABSTRACT}

Since the late fifteenth century European globalization of knowledge involves the supremacy of reason that comes together in a unit with modernity domination and colonialism. However, in Latin America they have always been developed epistemic response times of the process of globalization of knowledge modern and colonial. The origins of alternative thinking are at the very roots of the colonization of America. In Latin America and a time of discussion and criticism is opened, a plurality of perspectives that involve the development of proposals to distance themselves from Eurocentric discourse tested.

KEYWORDS: Modernity, social knowledge, epistemic discourse, Latin America. 
a relación modernidad y conocimiento es fundamental para comprender la emergencia de un discurso epistémico en América Latina frente a la hegemonía de la perspectiva eurocéntrica, dinámica que empieza a tener significación desde el siglo pasado y hoy alcanza resonancia internacional. El nudo entre modernidad y conocimiento subraya la particularidad de los profundos cambios históricos que vienen produciéndose en la visión del mundo y los valores de la episteme del siglo XXI.

El trabajo se propone esbozar algunas ideas preliminares sobre el desarrollo de la modernidad y conocimiento social. De esta forma, interesa presentar un recuento histórico de la confluencia de la relación entre modernidad y conocimiento que sirva de fundamento para exponer la irrupción de un pensamiento des/colonial en América Latina que cuestiona el eurocentrismo.

\section{Bases del discurso eurocéntrico}

Modernidad y conocimiento social en América Latina se conectan directamente con el proceso de universalización del saber europeo. Desde fines del siglo XV la conquista de América no solo significó la destrucción y dominación de pueblos y tierras sino, principalmente, involucró el desarrollo de una nueva visión del mundo moderno y colonial, encarnó la dominación de una manera de pensar y una forma de producir conocimiento. A la vez que se universalizaba el tipo de saber moderno, la conquista llevaba la subordinación y destrucción de los conocimientos nativos de América Latina, como lo expone Walter Benjamim", "no existe documento moderno de cultura que no sea a la vez documento de barbarie", la hegemonía del discurso de la razón moderna encierra en una unidad descubrimientos y mundialización de saberes europeizados; pero, también, coacción y dominio de los otros conocimientos indígenas².

Entre los siglos XVI y XVII se desarrollan la cognición y principios éticos del intelecto moderno universal, imponiendo su hegemonía por quinientos años. La episteme moderna tiene su impulso definitivo con René Descartes, considerado el pensador más influyente a partir del siglo XVII, aunque sus antecedentes pueden encontrarse en la filosofía iberoamericana del siglo anterior, entre los que destaca Francisco Suárez ${ }^{3}$. En efecto, Descartes en El discurso del método (1637) define el "yo pienso, luego existo" como el nuevo fundamento del conocimiento que cuestiona la autoridad divina para pasar a ser un resultado de la capacidad racional del «yo» humano. Es una episteme universal porque la naturaleza

Walter Benjamín: "Tesis de filosofía de la historia", Ensayos escogidos, Sur, Buenos Aires, 1967, p. 46.

Immanuel Wallerstein: Universalismo europeo. El discurso del poder, Siglo XXI Editores, Madrid, 2007.

Descartes es el heredero de la filosofía lbero-americana en particular del jesuita español F. Suarez autor de Disputaciones metafísicas (1597)“la primera antología moderna"y de el primer debate público y central filosófico de la Modernidad de Valladolid (1550) entre Ginés de Sepúlveda y Bartolomé de las Casas. Enrique Dussel:"Meditaciones anti-cartesianas: sobre el origen del anti-discurso filosófico de la Modernidad", Tabula Rasa, № 9, Bogotá, 2008. AlvarezUría, Fernando: El reconocimiento de la humanidad. España, Portugal y América Latina en la génesis de la modernidad, Morata, Madrid, 2015. 
humana se concibe como una dualidad radical entre espíritu y cuerpo, que supone la primacía del "yo" o espíritu sin referencia particular alguna, sin cuerpo, más allá del tiempo y el espacio, por encima de las realidades específicas. La episteme cartesiana originó la convicción de un "yo" que genera un conocimiento universal, aunque se trate propiamente de la hegemonía del saber europeizado. Asimismo, en el "yo pienso" subyace la idea que los "otros no piensan", los indígenas están desprovistos de la capacidad del ser de producir conocimientos modernos, sus saberes son bárbaros y son absolutamente dispensables ${ }^{4}$. La matriz cartesiana impone una episteme fundada en el mecanicismo, el mundo se simplifica en partes separadas y aisladas, destruyendo el paradigma holístico que hundía sus raíces desde la antigüedad. La racionalidad moderna tiene la capacidad de saber y conocer el mundo y encierra, también, la dominación sobre las otras formas pensamientos, los liquida y somete para imponerse. De esa forma, se estructura la episteme moderna universalizada entre el saber europeizado dominante que, a la vez, se reproduce históricamente con la colonialidad de las formas de conocimiento indígena de América Latina.

En el desarrollo de la hegemonía del pensamiento europeo el "yo pienso" deviene en Immanuel Kant en el yo "trascendental"5 de Crítica de la razón pura (1781), una de las mayores obras de la filosofía moderna. El yo "trascendental" se define por los principios a priori que determinan el pensamiento racional, condiciones innatas de espacio y tiempo. El conocimiento racional es posible porque el "yo" europeo"blanco" dispone de una "lógica trascendental" de categorías congénitas de tiempo y espacio, mientras que los otros sujetos "indios amarillos", "negros" y "pueblos americanos" carecen o están muy por debajo del "talento" humano 6 . Para Kant solo el sujeto europeo posee la capacidad "trascendental" del pensamiento racional, con ello introduce el criterio de distinción esencial de sometimiento y dominación cognitiva de los otros no europeos, explicado por las condiciones de inferioridad natural de las poblaciones indígenas.

De la misma forma, Hegel señala en el siglo XIX que el conocimiento racional, si bien no corresponde a un pensamiento a priori, como en Kant, es resultado del movimiento histórico de las ideas, del espíritu racional, que se inicia en oriente y en "Europa es absolutamente el término de la historia universal"7, África y América Latina quedan fuera por ser pueblos bárbaros y primitivos, Dussel señala que para Hegel hasta las piedras, la fauna y la flora son más brutales y salvajes en Latinoamérica ${ }^{8}$. El sujeto europeo es el único que posee la capacidad de elaborar un pensamiento racional, los otros pueblos no solo producen saberes inferiores sino, fundamentalmente, el sujeto carece de los atributos naturales para ello.

4 Nelson Maldonado-Torres: "Sobre la colonialidad del ser: contribuciones al desarrollo de un concepto", Santiago Castro-Gómez / Ramón Grosfoguel (Editores): El giro decolonial. Reflexiones para una diversidad epistémica más allá del capitalismo global, Bogotá, Universidad Javeriana - Instituto Pensar,Universidad Central (IESCO-UC), Siglo del Hombre Editores, 2007, p. 144.

5 Inmanuel Kant: Crítica de la razón pura, Buenos Aires, Ediciones Cohhue, 2007, pp. 87-90.

6 Immanuel Kant: Antropología, Madrid, Alianza Editorial, 2004. Un debate mayor en José Santos Herceg: "Inmanuel Kant: Del racialismo al racismo", Thémata. Revista de Filosofía. № 43, Universidad de Sevilla, 2010, pp. 403-416.

7 Georg Wilhelm Friedrich Hegel: Lecciones sobre la filosofía de la historia universal [1833], Tecnos, Madrid, 2005, p. 308.

8 Enrique Dussel: 1492. El encubrimiento del otro. Hacia el origen del "mito de la modernidad", Plural, La Paz, 1994, p. 16. 
Para los principales filósofos de la modernidad la universalización del saber es la superioridad de la cognición europeizada, que discurre sobre el sometimiento epistémico e inferiorización ontológica del sujeto de América Latina.

\section{Eurocentramiento del saber racional}

El proceso de universalización europeo del "yo pienso" supuso previamente un histórico "yo conquisto", 150 años anteriores de conquista y violencia ${ }^{9}$, un periodo de tiempo que permitió crear las condiciones de la superioridad del pensamiento moderno. El "yo conquisto" es en realidad un "yo conquisto" epistémico mundial, no solamente es una dominación de personas y tierras sino, primordialmente, se trata de un "yo conquisto" subjetivo. Proceso que posibilitó la combinación de las ideas de la ilustración europea y de los fundamentos de la inferioridad ontológica de los pueblos indígenas, que llevó a anudar razón con dominación y modernidad con colonialidad. Dinámica histórica que se inició en el renacimiento y tuvo su conformación definitiva con la conquista de América, donde se trazaron en un mismo fenómeno epistémico las bases de la hegemonía del modo de pensar occidental y el sometimiento de los otros saberes.

El renacimiento es la etapa histórica de cambio cultural que Europa recupera el pensamiento humanista e inicia un nuevo momento reflexivo y, además, envuelve la destrucción de los propios saberes populares europeos, más de 100,000 brujas fueron quemadas vivas entre los siglos XV y XVI ${ }^{10}$. La caza de bujas siguió el camino trazado por la Reforma protestante, aconteció con fuerza inusitada en Francia e Italia, Alemania, Suiza, Inglaterra, Escocia, Suecia y fue mucho menor en los países más católicos como España y Portugal. De esa forma, el discurso de la razón renacentista expresa la expansión de las ideas humanistas, científicas y tecnológicas de Copérnico, Descartes, Miguel Ángel, Leonardo da Vinci, Galileo, etc., e igualmente representó el proceso de destrucción, sometimiento y deslegitimación de conocimientos de los pueblos. Principalmente fueron mujeres las que se quemaron, aunque hubo muchos hombres que fueron llevados a la hoguera, se trató de la liquidación del pensamiento de curanderos, chamanes y de las formas de conocimientos de fines del Medioevo europeo que les permitían a las gentes nacer, reproducirse, curarse y alimentarse. El renacimiento además de llevar la ruina económica del campesino produjo la liquidación, sometimiento y deslegitimación de sus formas de pensar, de los saberes populares ${ }^{11}$. La quema de brujas es el primer acto del discurso moderno que conllevó la destrucción de los otros saberes. Es el momento que la razón y dominación se integran, que acarreó la separación radical de sociedad con naturaleza y trajo la pérdida de poder de las mujeres en el control de la vida (reproducción, enfermedad y alimentación). Porque las mujeres a través de la reproducción

9 Enrique Dussel: 1492: El encubrimiento del otro. Hacia el origen del "mito de la modernidad", La Paz, Plural Editores, 1994.

10 Esther Cohen: Con el diablo en el Cuerpo. Filósofos y brujas en el Renacimiento, Taurus, México, 2013, p. 27.

11 Marvin Harris: Vacas, cerdos, guerras y brujas. Los enigmas de la cultura, Alianza Madrid, 1998, pp.140-141. 
tienen una relación especial con el mundo natural, hace que su cuerpo tenga una sintonía más intensa, obliga a reconocer que hay fuerzas superiores al sujeto y que se tiene que aprender a convivir con ellas. Siempre las mujeres históricamente fueron recolectoras de plantas, curanderas y parteras, están más cerca de la práctica y del conocimiento de la reproducción de la vida ${ }^{12}$. El renacimiento anuncia la ilustración y la razón moderna pero, sobre todo, implicó la imposición de una nueva visión del mundo basada en la separación tajante de la sociedad con la naturaleza y la pérdida de ciertas libertades y autonomía de las mujeres.

Un segundo momento, es la destrucción en el siglo XV de otra cultura/civilización no occidental, ya no se trata solo de saberes populares, sino que se asiste a la liquidación de formas de pensamiento del mundo islámico, que tuvo su apogeo entre los siglos VIII y $\mathrm{XV}$, con su centro en Bagdad y el dominio de los flujos mercantiles y culturales en todo el medio oriente, desde Filipinas, el norte del África, la cuenca del Mediterráneo y la península Ibérica, desarrolló un mundo urbano e intelectual intenso, sobre todo de las matemáticas, la historia y la filosofía ${ }^{13}$. En el Califato de Al Ándalus se traducían y discutían Aristóteles, mientras que el Medioevo europeo lo impedía y reprimía, la novela de Umberto Eco lo describe magistralmente ${ }^{14}$. La "reconquista"y expulsión del Califato de Al Ándalus por los Reyes Católicos supone el sometimiento, la destrucción de saberes populares y, principalmente, de la cognición del mundo árabe que había permanecido en Iberia durante 8 siglos. El Califato de la península Ibérica permitió la enriquecedora tolerancia y pluralidad social y cognitiva entre cristianos, árabes y judíos. Fue la "reconquista" de los Reyes Católicos la que destruyo la coexistencia cognoscitiva y, en términos políticos, lo que sería un naciente Estado plurinacional. Se impuso la intransigencia totalitaria, mediante la expulsión de judíos y árabes, y el dominio político de una religión, una idea, una nación. Además, la "reconquista" buscó destruir y borrar todos los logros del conocimiento acumulado por el mundo árabe, se quemaron públicamente las bibliotecas de Córdoba con 400,000 volúmenes y la de Granada con 250,000 libros, que contenían todo el acervo humanístico del mundo conocido en los diferentes campos del saber ${ }^{15}$. Desde entonces, la "reconquista" ató exclusivamente modernidad con Europa y la cultura occidental, además de liquidar la tolerancia epistémica e imponer la destrucción de otras culturas.

El desarrollo de la modernidad involucró violencia y sometimiento de los saberes populares europeos y de la cultura islámica. En ese camino, la conquista y dominación europea en América supuso la subordinación cognitiva y, además, la negación del otro "indígena" del nuevo mundo. Cuando Cristóbal Colon llegó a América en 1492 escribió en su diario que "Esta gente no tiene secta"16, no poseen religión, son sujetos sin alma,

12 Silvia Federici: Calibán y la bruja .Mujeres, cuerpo y acumulación primitiva, Traficantes de Sueños, Madrid, 2010.

13 Enrique Dussel: Política de la liberación. Historia mundial crítica, Editorial Trotta, Madrid, 2007, 186 - 268. Enrique Dussel: Materiales para una política de la liberación, UANL - Plaza y Valdés, Madrid, 2007, 195-212.

14 Humberto Eco: El nombre de la rosa, Lumen, Barcelona, 1982.

15 Esteban Martínez Almirón: Legado gnomónico de Al-Ándalus. Personajes, documentos y materiales, Reloj Andalusí, Córdoba, 2014, p. 31.

16 Cristóbal Colón: Los cuatro viajes del Almirantey su testamento, Edición de lgnacio B. Anzoátegui, Espasa Calpe, Madrid, 1991, “Diario 12-11-1492". http://www.cervantesvirtual.com/obra/los-cuatro-viajes-del-almirante-y-su-testamento--0/ 
sin voluntad, carentes de derechos, únicamente pueden considerarse objetos de explotación y mercantilización como la naturaleza. La negación de la alteridad del otro llevó a la demolición y subordinación de los pensamientos populares y culturales diferentes, Inca, Azteca y Maya pero, lo más importante, supuso la dominación e inferioridad ontológica de los pueblos indígenas, que por su naturaleza carecen de las capacidades de producir una episteme racional, porque son seres no humanos o subhumanos.

En la famosa polémica entre Bartolomé de las Casas y Ginés de Sepúlveda de 1550, en Valladolid, se estableció en forma definida la inferioridad ontológica del indígena del nuevo mundo y, por lo tanto, de su episteme. Ginés de Sepúlveda va a argumentar que no tienen alma los negros y los nativos de América, son "bárbaros" en "inferioridad humana". Bartolomé de las Casas establece que los negros no tienen alma, mientras que los indígenas de América Latina son "bárbaros" en "diferencia cultural", seres inferiores por su identidad, son culturas y pueblos salvajes sin capacidad de la humanidad europea ${ }^{17}$. Proceso de infrahumanidad racial por segregación de la identidad cultural que llegó hasta la Solución final hitleriana en 1945. De esta forma, en ese debate histórico se definieron dos formas de inferioridad ontológica, una directamente racializada por su biológica y la otra racializada por su identidad cultural.

El "yo pienso" supuso 150 años de"yo conquisto", la expansión de la razón europea se conjugó con la dominación epistémica y ontológica de los pueblos de América. En la conquista y dominación de los pueblos indígenas se destruyeron y quemaron miles de quipus incas y códices mayas que contenían los grandes logros cognoscitivos de las culturas de América Latina y la "extirpación de las idolatrías" condenó los saberes nativos como obras del demonio, lo que facultó la práctica de extermino epistémico. Precisamente porque las culturas indígenas tienen una visión holística del mundo, de unidad de lo inmanente con lo trascendente, de lo material y lo espiritual, del hombre con la naturaleza, que la razón moderna destruyó en la Europa renacentista y con su universalización la violencia epistémica se extendió al nuevo mundo.

La conquista, a lado de la destrucción masiva de conocimientos y saberes, produjo la inferioridad ontológica del hombre de América Latina. La modernidad significó la universalización de la episteme europea, pero también conllevó barbarie y colonialidad.

\section{Respuestas epistémicas}

Desde fines del siglo XV la mundialización del saber europeo comporta la supremacía de la razón que confluye en una unidad con dominación y la modernidad con colonialidad. Sin embargo, en América Latina siempre se han desarrollado momentos de respuesta epistémica frente al proceso de universalización del saber moderno y colonial.

17 Patricio Lepe-Carrión: “Civilización y barbarie. La instauración de una'diferencia colonial'durante los debates del siglo XVI, y su encubrimiento como'diferencia cultural'", Andamios. Revista de Investigación Social, vol. 9, № 20, Universidad Autónoma de la Ciudad de México, 2012, pp. 63-88. 
Los orígenes de un pensamiento alternativo se encuentran en las mismas raíces de la colonización de América. La respuesta inmediata de un orden íntegramente diferente a la sociedad colonizada fue elaborada a partir del legado indígena por Felipe Huaman Poma ${ }^{18}$ en su Nueva corónica y buen gobierno de 1615. Más allá de la propuesta de autonomía del mundo andino, frente a la dinámica de la colonización de América que subrayaba el individualismo rescata la comunidad y las relaciones de reciprocidad. A la destrucción de la naturaleza que conducía el proyecto colonial se antepone la visión del ser humano como parte de la naturaleza, la gran comunidad de vida que incluye además del ser humano, la Pachamama (Tierra) y el Pachacamac (universo).) Si la perspectiva colonial del ser humano implicaba la separación radical del alma y cuerpo, para establecer la idea que algunas "razas" - las indígenas - y la naturaleza son inferiores porque están más próximas de la tierra y cuerpo, que otras superiores — las europeas - más cercanas del espíritu divino. Guaman Poma formula una perspectiva basada en la interrelación estrecha de la multiplicidad de las dimensiones del mundo que forman una totalidad, diferente a la mirada de la conquista europea. En la Nueva corónica el bien vivir es el proyecto epistémico alternativo andino radicalmente diferente al "vivir mejor" de la sociedad moderna colonial ${ }^{19}$. Es el primer momento fundamental de la formulación de un discurso de des/colonialidad.

Otra etapa histórica de confrontación con el eurocentrismo es la revolución de Haití (1789-1805) y su declaración Constitucional del 20 de mayo de 1804, además de constituirse en el inicio de la independencia en América Latina y el Caribe ${ }^{20}$, significa la "primera revolución global". La Constitución haitiana recogió la lucha triunfante de ese movimiento histórico: la independencia política contra la dominación colonial, la abolición del esclavismo, el triunfo de la población negra sobre la dominación de la raza inferior y la proclamación de una nueva nación. Representa la ruptura epistémica integral que cuestiona el universalismo de libertad e igualdad excluyente europeo, blanco y burgués, desde el particularismo de los esclavos afroamericanos enuncia la tolerancia y libertad de todos los pueblos sin distinción, definiendo que todos los ciudadanos"serán conocidos de ahora en adelante en más por la denominación genérica de Negros". De ahí que la independencia de Haití signifique "el proceso inicial del largo tiempo" de la des/colonialidad del poder ${ }^{21}$, de una modernidad que busca reintegrarse con los grandes valores de libertad e igualdad.

Aimé Cesaire, el gran pensador afrocaribeño del enclave francés de la isla Martinica en el Caribe, en 1956 elabora un manifiesto del pensamiento de des/colonialidad en su carta de renuncia al Partido Comunista Francés: "¿Provincialismo? En absoluto. No me en-

18 Felipe Guaman Poma de Ayala: Nueva corónica y buen gobierno, FCE, México, 2005, 3T.

19 Carolina Ortiz: "Felipe Guaman Poma de Ayala, Clorinda Matto de Turner, Trinidad Henríquez y la teoría crítica -sus legados a la teoría social contemporánea-", Yuyaykusun, №2, Departamento de Humanidades, Universidad Ricardo Palma, Lima, 2009, pp. 263-284. También puede consultarse el trabajo de Aníbal Quijano: "Bien vivir: entre el "desarrollo"yla des/colonialidad del poder", Cuestiones y horizontes. De la dependencia histórico-estructural a la colonialidad/ descolonialidad del poder, CLACSO, Buenos Aires, 2014.

20 Eduardo Grüner: La oscuridad y las luces. Capitalismo, cultura y revolución, Edhasa, Buenos Aires, 2010.

21 Aníbal Quijano: "América Latina en la Economía mundial", CLACSO, Buenos Aires, p. 206. "El bicentenario de una paradoja histórica", Tradición, № 11, Universidad Ricardo Palma, Lima, 2011, pp. 150-156. 
tierro en un particularismo estrecho. Pero tampoco quiero perderme en un universalismo descarnado. Hay dos maneras de perderse: por segregación amurallada en lo particular o por disolución en lo 'universal'. Mi concepción de lo universal es la de un universal depositario de todo lo particular, depositario de todos los particulares, profundización y coexistencia de todos los particulares"22. Proyecto epistémico que postula "desprenderse" del universalismo europeo y del control de la subjetividad, repensando la modernidad desde los pensamientos particulares y experiencias libertarias periféricas de América Latina y el mundo.

La crítica al universalismo abstracto tiene en José Carlos Mariátegui uno de sus momentos más reveladores, desde la particularidad andina va abordar al ser humano como una unidad tensional entre dos formas culturales, "el logos y el mito"23, que la modernidad eurocéntrica desune y opone como irreconciliables. Posición que Weber lo expone en su forma más acabada: "La intelectualización y racionalización [...]; significan que [...], no existen en torno a nuestra vida poderes ocultos e imprevisibles, sino que, por el contrario, todo puede ser dominado mediante el cálculo y la previsión. Esto quiere decir simplemente que se ha excluido lo mágico del mundo. A diferencia del salvaje, para quien tales poderes existen, nosotros no tenemos que recurrir ya a medios mágicos para controlar los espíritus o moverlos a piedad. Esto es cosa que se logra merced a los medios técnicos y a la previsión"24. En cambio, para Mariátegui la vida humana se comprende por la unidad holística de razón y logos con voluntad, fantasía e imaginación, lo humano es un ser complejo, heterogéneo, portador de sueños y logos. Explica que la sobrevaloración de la racionalidad hegemónica genera un sujeto sin interioridades, sin complejidades, un ser unidimensional que privilegia el sometimiento de los dioses y de la naturaleza, donde lo imaginario ni el mito forman parte: "ni la razón ni la ciencia pueden ser un mito. Ni la razón ni la ciencia pueden satisfacer toda la necesidad de infinito que hay en el hombre. La propia razón se ha encargado de demostrar a los hombres que ello no les basta"25. Enfoque epistémico trascendental, el conocimiento de la realidad es mayor que el simple saber europeizado, comprender la complejidad del mundo comporta sobrepasar la razón eurocéntrica, apelando a la unidad diversa múltiple del ser, del pensar y sentir, del logos y mito.

Otro momento central del pensamiento latinoamericano que emerge frente al universalismo europeizado es el desarrollo de la teoría de la dependencia en los años sesenta. La teoría de la dependencia plantea el desarrollo y subdesarrollo como dos aspectos de una realidad esencialmente económica. Aquí Aníbal Quijano rompe rápidamente con esa visión unilateral, elabora una propuesta totalizadora de la existencia social al destacar el

Aimé Césaire: Discurso sobre el colonialismo, Akal, Madrid, 2006, p. 84.

Aníbal Quijano: "Prólogo", en José Carlos Mariátegui. Textos Básicos, F. C. E., Lima, 1991, p. IX.

Max Weber: El político y el científico, Alianza, Madrid, 1997, pp. 199-200.

José Carlos Mariátegui: El alma matinal y otras estaciones del hombre de hoy, Ed. Amauta, Lima, 1983, p. 23. 
tema cultural en sus trabajos sobre la cholificación ${ }^{26}$ y subrayar la dependencia estructural ${ }^{27}$, idea que no trata de una forma de dominación exclusivamente por medios coercitivos, sino manifiesta una manera de dominación epistémica que busca que el imaginario eurocéntrico naturalice la dominación, de tal forma que los dominados abandonen su propia cultura, olviden lo que son y dejen de lado su pasado, proyecto que quiere someter la cultura andina, es decir convertir a los hombres de nuestro continente en hombres hechos a semejanza de Europa. Se resalta la excepcionalidad de la episteme latinoamericana que concibe la modernidad capitalista como resultado de las transformaciones ocurridas en la "totalidad del mundo" contemporáneo.

Un punto de inflexión esencial en el discurso epistémico de América Latina es la "teoría cognitiva" de la autopoiesis elaborada en la década del sesenta del siglo pasado por Humberto Maturana ${ }^{28}$, radicalmente distinto al enfoque mecanicista. El dualismo radical cartesiano entre espíritu y cuerpo va a ser superado por la perspectiva holística de la "Escuela de Santiago", definiéndose como dos aspectos complementarios del mismo fenómeno, parte de la propia evolución del ser vivo. Las sociedades y todo ser vivo son "sistemas que se producen a sí mismos continuamente"29. Los sistemas autopoiéticos se autoorganizan y generan su propia red de interacciones que las transforma como una totalidad que, en forma simultánea, se autoproduce y tienen la capacidad de configurar el flujo de sus individualidades que lo componen. Como sistema vivo material y espiritual es resultado de un proceso de aprendizaje, el proceso cognitivo es el modo como el organismo autoproduce la vida — planta, animal, humana y la sociedad —, la manera que permanentemente renuevan sus componentes y su identidad estructural en una dinámica cíclica. En ese sentido, la actividad mental no es una representación solo espiritual, sino un continuo proceso de la praxis de vivir y en la que participa todo la estructura del organismo, la vivencia que dan las emociones, las sensaciones, las disposiciones corporales y la cognición de la misma experiencia de vida.

A partir de la conquista de América se universalizó un modo de pensar moderno que basó su hegemonía en la racionalidad europeizada y el cual desde el lado subordinado siempre trazó respuestas epistémicas alternativas, del que hemos señalado algunas de ellas, que permitieron seguir imaginando otra racionalidad holística fundada en la libertad e igualdad social.

26 Aníbal Quijano: "La emergencia del grupo cholo y sus implicancias en la sociedad peruana" y"Lo cholo y el conflicto cultural en el Perú", Dominación y cultura. Lo cholo y el conflicto cultural en el Perú. Mosca Azul Editores, Lima, 1980, [1964].

27 Aníbal Quijano:“Dominación y cultura (Notas sobre el problema de la participación cultural)”, en Dominación y cultura. Lo cholo y el conflicto cultural en el Perú, Mosca Azul Editores, Lima, 1980 [1971], p. 38.

28 Humberto Maturana y Francisco Varela: De máquinas y seres vivos. Autopoiesis: la organización de lo vivo, Editorial Universitaria, Santiago, 2006. Humberto Maturana y Francisco Varela: El árbol del conocimiento, Editorial Universitaria, Santiago, 2006. Humberto Maturana y Bernhard Pörksen: Del ser al hacer. Los orígenes de la biología del conocer, J.C. Sáez, Santiago, 2004. Una discusión más amplia en Fritjof Capra y Pier Luigi Luisi: A visão sistêmica da vida: uma concepção unificada e suas implicações filosóficas, políticas, sociais e econômicas, Cultrix, São Paulo, 2014, pp. 316-341. Humberto Maturana: Transformación en la convivencia, Dolmen Ediciones, Santiago, 2002, p. 92. 


\section{Discurso epistémico latinoamericano}

El patrón epistémico moderno/colonial que impuso su hegemonía universal ha empezado a hacer crisis desde la segunda Guerra Mundial. Se abre una etapa de bifurcación teórica del pensamiento europeizado que describe que el sistema puede ir en varias direcciones, su lógica, estabilidad y sentido se han roto. En un principio, durante los años ochenta y noventa florecieron algunas perspectivas que rozaban con el escepticismo o irracionalismo en el pensamiento social latinoamericano, como la posmodernidad y los estudios culturales, que ponían énfasis en cierto distanciamiento de la razón en el conocimiento y subrayaban la descripción local dejando de lado toda forma de universalismo ${ }^{30}$. El debate actual en América Latina ha puesto de relieve que los nuevos enfoques cognoscitivos se fundan en la fuerza de la razón y en los aportes de la complejidad que pone en cuestión la hegemonía del modelo cartesiano newtoniano de la racionalidad mecanicista, Pablo González Casanova lo denomina las nuevas ciencias ${ }^{31}$, Humberto Maturana ${ }^{32}$ sistemas autopoiéticos e Immanuel Wallerstein lo ha precisado como las ciencias de la complejidad: "lo que es esencial poner de relieve en los estudios de la complejidad es que de ningún modo rechazan el análisis científico, sólo el determinismo newtoniano" ${ }^{\prime 33}$.

En América Latina se abre un momento de discusión y crítica, se ensayan una pluralidad de perspectivas que conllevan el desarrollo de propuestas que se distancian del discurso eurocéntrico. En la región las ideas subrayan la vigencia de la racionalidad, aunque vinculada inherentemente a la libertad, tolerancia e igualdad social. A partir de América Latina empieza a gestarse una nueva episteme holística que anuncia un horizonte histórico de una sociedad definida por los grandes ideales de humanidad.

En esa dirección, se destaca la perspectiva neoliberal que se desarrolla a partir de la segunda mitad de los setenta, patrocinado por el Consenso de Washington, asume algunos matices latinoamericanos que es importante destacar. Concepción que tuvo su campo de experimentación en Chile durante el gobierno dictatorial de Augusto Pinochet, solo después se expande en Inglaterra, Estados Unidos y se convierte en una especie de credo global. El neoliberalismo busca recuperar la hegemonía de la razón eurocéntrica e

30 Julio Mejía: Sociedad y conocimiento. Los desafíos de la sociología latinoamericana, UNMSM | Facultad de Ciencias Sociales, Lima, 2009. José Sánchez Parga: Una 'Devastación de la inteligencia.' Crisis y crítica de las ciencias sociales. Abya-Yala, 2007, Quito, pp. 201-235. Catherine Walsh (edit.): Estudios culturales latinoamericanos, Universidad Andina Simón Bolívar / Abya-Yala, Quito, 2003. Carlos Reyna: Apogeo y decadencia de los estudios culturales. Una visión antropológica. Gedisa, Barcelona, 2000; Roberto Follari: "Estudios culturales, transdisciplinariedad e interdisciplinariedad (¿hegemonía en las ciencias sociales latinoamericanas?)", Utopía y Praxis Latinoamericana, Año 6, № 14, Maracaibo, 2001, pp. 40-47. Eduardo Grüner: "Introducción", Fredric Jameson, Slavoj Žižek: Estudios culturales. Reflexiones sobre el multiculturalismo, Buenos Aires, Paidós, 1998; otro trabajo del mismo autor: El fin de las pequeñas historias, Buenos Aires, Paidós, 2002; Nicolás Casullo: Modernidad y cultura crítica, Buenos Aires, Paidós, 1998; Roberto Follari: Teorías débiles (para una crítica de la deconstrucción y de los estudios culturales), Homo Sapiens, Rosario, 2002.

31 Pablo González Casanova: Las nuevas ciencias y las humanidades. De la academia a la política, Anthropos - IIS de la UNAM - Editorial Complutense, Barcelona, 2004.

32 Humberto Maturana: Transformación en la convivencia, Dolmen Ediciones, Santiago, 2002, p. 92.

33 Immanuel Wallerstein: Capitalismo histórico y movimientos antistémicos. Un análisis del sistema-mundo, Akal, Madrid, 2004, p. 194. 
imponer el dominio absoluto de un universalismo abstracto. Desde los ochenta, en América Latina su exponente más importante, Hernando de Soto, reelabora el discurso neoliberal con La revolución informa ${ }^{34}$, a la perspectiva del individuo libre en el mercado sin las interferencias del Estado, incorpora los derechos de propiedad, la informalidad empresarial y, sobre todo, el capitalismo popular. El neoliberalismo nativo propendió individualismo económico, mercados desregulados y, sobre todo, emprendedores populares, nunca se propuso una sociedad más igualitaria y de creciente democracia, su contenido es una sociedad de "Ciudadanos sin República"35. Es decir, propuso un camino de crecimiento y modernización económica que "incluya" lo informal, nunca suscribió las promesas de la modernidad de libertad e igualdad social.

Es importante destacar el pensamiento crítico europeo actual, discurso que cuestiona el orden establecido o algunos de sus aspectos fundamentales en nombre de los valores de igualdad, libertad y justicia ${ }^{36}$. Es más, desde fines de los años ochenta en América Latina toda forma de crítica entró en rápida decadencia, disgregación y sin mayor debate, condicionada por la derrota de los socialismos realmente existentes. Momento dominado por el pensamiento ensayístico ecléctico, con posturas que transcurren por caminos posmarxistas y en la necesidad de incorporar ideas contestatarias del mundo periférico ${ }^{37}$. En esa dirección, es ilustrativo El capital del siglo XXI de Thomas Piketty ${ }^{38}$ que de forma definitiva ha desarticulado los argumentos teóricos del neoliberalismo, demuestra analíticamente que el "1\% más rico" es resultado de la modernidad global, sistema que lleva únicamente a la expansión de desigualdades extremas, más bien desarrolla un capitalismo oligárquico porque el capital neto familiar siempre tendrá un crecimiento mayor que el conjunto del país y, en ese mundo para poder sobresalir únicamente quedan dos salidas: ser genio o ser corrupto ${ }^{39}$, es decir apelar a la violencia, narcotráfico y criminalidad. De alguna forma, la obra de Piketty renueva el pensamiento europeo porque permite pensar más allá del neoliberalismo. Por otra parte, James Lovelock ${ }^{40}$, en La venganza de la tierra. La teoría de la Gaia y el futuro de la humanidad, señala que el planeta es un sistema autoregulado entre lo biológico, geográfico y químico que sostiene la vida y, parecería, que ese equilibrio

34 Hernando de Soto: El Otro Sendero. La revolución informal, El Barranco, Lima, 1986.

35 Alberto Vergara: Ciudadanos sin República. ¿Cómo sobrevivir en la jungla política peruana?, Planeta, Lima, 2013, pp. 17-28.

36 Carlos Altamirano: "Encuesta sobre el pensamiento crítico en América Latina. Crítica y Emancipación Revista Latinoamericana de Ciencias Sociales, Año I,N², Buenos Aires, 2009, p.14.

37 Se destaca, la teoría del acontecimiento de Badiou, la perspectiva de Pierre Bourdieu, el poscolonialismo de Bhabha y Spivack, el neomarxismo de Holloway, la crítica de Chosnky, el lacanianismo de Žižek y el Imperio y la Multitud de Hardt y Negri. Claudia Luz Piedrahita Echandía, Álvaro Díaz Gómez y Pablo Vommaro (Compiladores): Pensamientos críticos contemporáneos: Análisis desde Latinoamérica, Universidad Distrital Francisco José de Caldas - CLACSO, Bogotá, 2015. Göran Therborn:"Después de la dialéctica la teoría social radical en un mundo poscomunista", New Left Review No 43. Marzo/abril, 2007, pp. 59-106.

38 Thomas Piketty: El capital del siglo XXI, FCE, México, 2015.

39 Thomas Piketty: "Utilizando una obra de Balzac.'¿Triunfar hoy? 0 eres un genio o un corrupto': Piketty explica el siglo XXI", El Confidencial, 29 de abril 2014, http://www.elconfidencial.com/alma-corazon-vida/2014-04-29/ triunfar-hoy-o-eres-un-genio-o-un-corrupto-el-guru-de-moda-explica-el-futuro_122640/

40 James Lovelock: La venganza de la tierra. La teoría de la Gaia y el futuro de la humanidad, Planeta, Barcelona, 2007. 
autopoiético se ha roto, poniendo en peligro toda forma de vida en los próximos 100 años. La teoría crítica fundada en la racionalidad del análisis científico vuelve a descifrar los resortes de la explotación y dominación del mundo contemporáneo, lo que Aníbal Quijano denomina el "monstruo histórico" y "monstruo climático"41 como las mayores amenazas de la modernidad global.

Los estudios étnicos son otra perspectiva que irrumpe frente al discurso del pensamiento moderno universal, que se desenvuelven en algunos Departamentos de las Universidades en los Estados Unidos ${ }^{42}$. Los estudios étnicos son expresión de la presión de los movimientos sociales y de protesta de fines de la década de los sesenta, producto de la discriminación y la afirmación de la identidad de los grupos segregados en Norteamérica como los negros, indígenas, puertorriqueños, mujeres, chicanos, chinos y latinos. La intención central de los estudios étnicos es producir un conocimiento interdisciplinario desde los sujetos inferiorizados y sometidos, recuperar una epistémica que incluya la libertad de género y la tolerancia de todas las minorías sociales. Nacen en un contexto de desarrollo de los "estudios de área" impulsados por las políticas estatales para conocer la diversidad regional del tercer mundo con la intención de propiciar las estrategias necesarias para extender la dominación norteamericana durante el periodo de la guerra fría ${ }^{43}$. Los "estudios de área" son impuestos desde la modernidad del primer mundo para controlar y dominar, en cambio para los estudios étnicos la modernidad es la condición indispensable para empoderar a las comunidades racializadas, reforzar sus identidades y ganar libertades.

El neodesarrollismo o "desoccidentalización"44 es el discurso que reformula la modernización capitalista desde los propios valores nativos de cada región, criticando el neoliberalismo ${ }^{45}$, hace eco de las experiencias de Bolivia, Ecuador, Venezuela, de alguna forma, de China, Singapur y Asia. En efecto, dejan de lado el discurso universal del liberalismo, las recomendaciones del Fondo Monetario Internacional, Banco Mundial, más bien recogen una mayor presencia del Estado en las políticas de desarrollo, rechazan las formas abiertas de racismo occidental e incorporan aspectos del legado histórico propio, del mundo andino el buen vivir en el Estado Plurinacional o el confucionismo en el Estado Civilizatorio Chino. Pareciera que en América Latina la expresión teórica mayor es la del boliviano Álvaro García Linera ${ }^{46}$, aunque la predominancia del extractivismo copa la eco-

41 Aníbal Quijano: "Presentación. Un nuevo debate latinoamericano", Des/colonialidad y bien vivir. Un nuevo debate en América Latina, Fondo Editorial URP, Lima, 2014.

42 Immanuel Wallerstein: Impensarlas ciencias sociales, Siglo XXI - UNAM, México, 1999, p. 110. Nelson Maldonado-Torres: "Pensamento crítico desde a subalteridade: os estudos étnicos como ciências descoloniais ou para a transformação das humanidades e das ciências sociais no século XXI", Afro-Ásia, № 34, Universidade Federal de Baia, 2006, pp. 105-129.

43 Mabel Moraña:Inscripciones críticas. Ensayos sobre cultura latinoamericana, Editorial Cuarto Propio, Santiago, 2014, Cap. 7.

44 Walter Mignolo:"Desobediencia epistémica y descolonización de las ciencias sociales", Rodrigo Cordero (Editor): Formas de comprender el presente, Ediciones Universidad Diego Portal, Santiago, 2012, pp. 23-50. Walter Mignolo: “Hacia la cartografía de un nuevo mundo: pensamiento descolonial y desoccidentalización (un diálogo con Walter Mignolo). Entrevista realizada por Francisco Carballo", Otros Logos. Revista de Estudios Críticos, № 3, Universidad Nacional de Camahue, 2012, pp. 263-264.

45 Kishore Mahbubani: ¿Pueden pensar los asiáticos?, Siglo XXI, México, 2002 (1998). También del mismo autor: El nuevo hemisferio asiático. El irresistible desplazamiento global hacia Oriente, Siglo XXI, México, 2013.

46 Álvaro García Linera: Democracia, Estado y nación, Vicepresidencia del Estado Plurinacional, La Paz, 2013. 
nomía, con la consiguiente destrucción de territorios indígenas, que tiene en la marcha en defensa del TIPNIS su mayor resistencia. En sus vertientes más consumadas de Asia el neodesarrollismo puede llevar a la negación de la democracia y de las libertades ${ }^{47}$. En general, la perspectiva neodesarrollista busca desvincularse del diseño global neoliberaly mantenerse en la modernización capitalista, subrayando su vinculación con los valores locales, aunque atentando gravemente contra la naturaleza y dejando de lado las libertades.

Finalmente, la teoría de la colonialidad del poder es el discurso latinoamericano más integral frente al universalismo europeizado. La teoría de la modernidad y colonialidad explica que desde fines del siglo XV en América se genera un nuevo patrón de poder históricamente particular que integra dos aspectos interrelacionados, un inédito sistema de explotación fundado en la hegemonía del capital y un original sistema de dominación social basado en la racialización de la población, que se constituye sobre la superioridad universal de la episteme de Europa occidental. La cultura moderna produjo la idea del indígena, un ser no humano o subhumano, bárbaro, desprovisto de derechos que es necesario civilizar, para lo cual hay que someter y en caso de resistencia aniquilar. Patrón de colonialidad que dio origen a las sociedades actuales de América Latina.

La colonialidad del poder se relaciona con la elaboración de una teoría para comprender América Latina como parte constitutiva de la modernidad. La colonialidad del poder significa el desarrollo de una teoría que explica la modernidad y delinea una posible alternativa ${ }^{48}$. La teoría de la colonialidad del poder es producto del camino cultural trazado en América Latina, hunde sus raíces en la originalidad de Aníbal Quijano y expresa el encuentro creativo con la rica tradición cognoscitiva de América Latina y, en particular, del mundo andino. Se remonta históricamente a la propuesta del bien vivir de Guaman Poma de Ayala, que destaca la importancia de la comunidad y la unidad intrínseca del hombre con la naturaleza, asume el mensaje de libertad y justicia social de la revolución haitiana, toma de José Carlos Mariátegui la totalidad del mundo como unidad de "el logos y el mito" en el ser humano y de lo inmanente y trascendente en la sociedad, subscribe de Aimé Césaire la crítica al eurocentrismo destacando el desarrollo de una universalidad concreta fundada en el particularismo de América Latina, subraya de la teoría de la dependencia la unidad de la diversidad integral entre política, economía y cultura, y de la autopoiesis la superación definitiva del dualismo cartesiano entre mente y materia para ser considerados dos aspectos complementarios del fenómeno de la vida.

Propuestas que permiten configurar una teoría más allá de la modernidad global. Una teoría holística de des/colonialidad que posibilita gestar un nuevo horizonte de sentido donde la razón solo pueda imaginarse con los postulados de una sociedad de libertad e igualdad.

47 Víctor López: La modernidad China. Fin del socialismo y desafíos de la sociedad de mercado, Siglo XXI, México, 2012, pp. 74-99.

48 Julio Mejía:"Colonialidad y des/colonialidad en América Latina. Elementos teóricos", Aníbal Quijano: Des/colonialidad y bien vivir. Un nuevo debate en América Latina, Editorial URP, Lima, 2014. 


\section{Conclusión}

Con la conquista del nuevo mundo, la modernidad epistémica se desarrolla simultáneamente en Europa y América, aunque bajo hegemonía de la primera y el sometimiento indígena. Modernización que definió un proceso histórico que marcó el desplazamiento de la razón histórica por el dominio eurocéntrico de la razón instrumenta ${ }^{49}$.

En las culturas indígenas la razón histórica o "razón objetiva" imperaba dentro de una visión holística del mundo como unidad de lo diverso, de lo inmanente y trascendente, y la racionalidad era inherente a la búsqueda de los ideales de sociedad de justicia social. La primacía de la "razón subjetiva" o razón instrumental se reduce a la posibilidad de calcular los medios adecuados para un fin individualizado en una visión mecanicista del mundo definida en función de cierta causalidad que opera linealmente sobre un objeto aislado del contexto, se abandona la totalidad y subraya las partes de manera absoluta, elimina toda posibilidad de concebir al individuo con responsabilidad y justicia social, solo interesa lograr un acto particular sin contorno. Los grandes ideales societales dejan de ser componentes inherentes de la razón, aunque persisten de manera formalizada y referencial separadas de las conductas aisladas de las personas. La razón deviene en la búsqueda egocéntrica del ser humano y se transforma en dominación, subyugando a la naturaleza y a los hombres.

Pareciera que la crisis de la modernidad global abre un nuevo tiempo histórico de bifurcación y emergencia epistémica, contrario al periodo anterior, que discurre de la razón instrumental hacia el desarrollo de la razón histórica. Son los nuevos movimientos de la sociedad los que vuelven a instituir los valores de libertad e igualdad, germinando un nuevo sentido histórico que empieza a revisar la subjetividad eurocéntrica y regresa para enlazar racionalidad con las máximas de libertad y justicia societal.

En particular, los indígenas cuestionan la idea de la raza como elemento de jerarquización social y se enfrentan a la mercantilización de la ecología para plantear la defensa de las condiciones de existencia y sobrevivencia del mundo. Las redes de "indignados" que se extienden desde el Norte del África a todo el mundo y América Latina instalan las demandas de igualdad como la aspiración central frente al " $1 \%$ más rico" de la sociedad. De la misma forma, feministas, homosexuales, pacifistas, anti-utilitarios, antiglobalización y otros desarrollan un conjunto de idearios, demandas y medidas de lucha que apuntan al reconocimiento de los derechos humanos, de los derechos de las mujeres, de los derechos de los homosexuales, de los derechos de la paz, solidaridad, reciprocidad y, en general, a la construcción de una sociedad más justa.

De modo particular, en la sociedad de América Latina se recrean nuevamente los valores libertarios y buscan hacerse parte inmanente de la racionalidad, dentro de una visión

49 Para América Latina lo describe Aníbal Quijano: Modernidad, identidad y utopía en América Latina, Sociedad y Política Ediciones, Lima, 1988, pp.45-69. De manera más general, Max Horkheimer: Crítica de la razón instrumental, SUR, Buenos Aires, 1973, pp. 15-68. 
holística de la heterogeneidad del mundo, que posibilita la emergencia de otra episteme del mundo y el desarrollo de un horizonte de sentido histórico alternativo.

\section{Referencias bibliográficas}

Altamirano, Carlos:"Encuesta sobre el pensamiento crítico en América Latina. Crítica y Emancipación Revista Latinoamericana de Ciencias Sociales, Año I, № 2, Buenos Aires, 2009.

ÁlVAREZ-URíA, Fernando: El reconocimiento de la humanidad. España, Portugal y América Latina en la génesis de la modernidad, Morata, Madrid, 2015.

Benjamin, Walter: "Tesis de filosofía de la historia", Ensayos escogidos, Sur, Buenos Aires, 1967.

CAPRA, Fritjof y Pier Luigi LUISI: A visão sistêmica da vida: uma concepção unificada e suas implicações filosóficas, políticas, sociais e econômicas, Cultrix, São Paulo, 2014.

CASULlo, Nicolás: Modernidad y cultura crítica. Buenos Aires, Paidós, 1998;

CÉSAIRE, Aimé: Discurso sobre el colonialismo, Akal, Madrid, 2006.

Colón, Cristóbal: Los cuatro viajes del Almirante y su testamento, Edición de Ignacio B. Anzoátegui, Espasa Calpe, Madrid, 1991. http://www.cervantesvirtual.com/obra/ los-cuatro-viajes-del-almirante-y-su-testamento--0/

COHEN, Esther: Con el diablo en el Cuerpo. Filósofos y brujas en el Renacimiento, Taurus, México, 2013.

DE SOTO, Hernando: El Otro Sendero. La revolución informal, El Barranco, Lima, 1986.

DE SOUSA SANTOS, Boaventura: Descolonizar el saber, reinventar el poder, Ediciones Trilce-Universidad de la República, Montevideo, 2010.

DESCARTES, René: El discurso del método, Sopena, Buenos Aires, 1964.

DUSSEL, Enrique: 1492: El encubrimiento del otro. Hacia el origen del "mito de la modernidad", La paz, Plural Editores, 1994.

DusSEL, Enrique: Enrique Política de la liberación. Historia mundial crítica, Editorial Trotta, Madrid, 2007.

DUSSEL, Enrique: Materiales para una política de la liberación, UANL - Plaza y Valdés, Madrid, 2007.

DUSSEL, Enrique: "Meditaciones anti-cartesianas: sobre el origen del anti-discurso filosófico de la Modernidad", Tabula Rasa, №9, Bogotá, 2008.

ECo, Humberto: El nombre de la rosa, Lumen, Barcelona, 1982.

FEDERICI, Silvia: Calibán y la bruja. Mujeres, cuerpo y acumulación primitiva, Traficantes de Sueños, Madrid, 2010.

FolLARI, Roberto: Teorías débiles (para una crítica de la deconstrucción y de los estudios culturales), Homo Sapiens, Rosario, 2002.

FolLARI, Roberto: "Estudios culturales, transdisciplinariedad e interdisciplinariedad (¿hegemonía en las ciencias sociales latinoamericanas?)", Utopía y Praxis Latinoamericana, Año 6, № 14, Maracaibo, 2001.

GarCía LINERA, Álvaro: Democracia, Estado y nación, Vicepresidencia del Estado Plurinacional, La Paz, 2013. 
GonzÁlez CASAnOva, Pablo: Las nuevas ciencias y las humanidades. De la academia a la política, Anthropos - IIS de la UNAM - Editorial Complutense, Barcelona, 2004.

GuAman Poma, Felipe: Nueva corónica y buen gobierno, FCE, México, 2005, 3T.

GRÜNER, Eduardo: La oscuridad y las luces. Capitalismo, cultura y revolución, Edhasa, Buenos Aires, 2010. GRÜNER, Eduardo: El fin de las pequeñas historias. Buenos Aires, Paidós, 2002.

GRÜNER, Eduardo: «Introducción». En Fredric Jameson, Slavoj Žižek: Estudios culturales. Reflexiones sobre el multiculturalismo. Buenos Aires, Paidós, 1998.

HARRIS, Marvin: Vacas, cerdos, guerras y brujas. Los enigmas de la cultura, Alianza, Madrid, 1998.

HEGEL, Georg Wilhelm Friedrich: Lecciones sobre la filosofía de la historia universal, [1833], Tecnos, Madrid, 2005.

HERCEG, José Santos: Inmanuel Kant: "Del racialismo al racismo", Thémata. Revista de Filosofía. № 43, Universidad de Sevilla, 2010, pp. 403-416.

HORKHEIMER, Max: Crítica de la razón instrumental, SUR, Buenos Aires, 1973.

KANT, Inmanuel: Critica de la razón pura, Buenos Aires, Ediciones Cohhue, 2007.

KANT, Inmanuel: Antropología, Madrid, Alianza Editorial, 2004.

LEPE-CARRIÓN, Patricio: "Civilización y barbarie. La instauración de una 'diferencia colonial' durante los debates del siglo XVI, y su encubrimiento como'diferencia cultural'", Andamios. Revista de Investigación Social, vol. 9, № 20, Universidad Autónoma de la Ciudad de México, 2012, pp. 63-88.

LÓPEZ, Víctor: La modernidad China. Fin del socialismo y desafíos de la sociedad de mercado, Siglo XXI, México, 2012.

LOVELOCK, James: La venganza de la tierra. La teoría de la Gaia y el futuro de la humanidad, Planeta, Barcelona, 2007.

MAHBUBANI, Kishore: El nuevo hemisferio asiático. El irresistible desplazamiento global hacia Oriente, Siglo XXI, México, 2013.

MAHBUBANI, Kishore: ¿Pueden pensar los asiáticos?, Siglo XXI, México, 2002 [1998].

MALDONADO-TORRES, Nelson: Sobre la colonialidad del ser: contribuciones al desarrollo de un concepto, Castro-Gómez, Santiago y Grosfoguel, Ramón (Editores): El giro decolonial. Reflexiones para una diversidad epistémica más allá del capitalismo global, Bogotá, Universidad Javeriana

- Instituto Pensar, Universidad Central (IESCO-UC), Siglo del Hombre Editores, 2007.

MALDONADO-ToRRES, Nelson: "Pensamento crítico desde a subalteridade: os estudos étnicos como ciências descoloniais ou para a transformação das humanidades e das ciências sociais no século XXI", Afro-Ásia, №34, Universidade Federal de Baia, 2006, pp. 105-129.

MARIÁTEGUI, José Carlos: El alma matinal y otras estaciones del hombre de hoy, Ed. Amauta, Lima, 1983.

MARTínEZ ALMIRÓN, Esteban: Legado gnomónico de al-Ándalus. Personajes, documentos y materiales, Reloj Andalusí, Córdoba, 2014.

MATURANA, Humberto y Varela, Francisco: De máquinas y seres vivos. Autopoiesis: la organización de lo vivo, Editorial Universitaria, Santiago, 2006 [1973].

Maturana, Humberto y Varela, Francisco: El árbol del conocimiento, Editorial Universitaria, Santiago, 2006. 
MATURANA, Humberto y PÖRKSEN, Bernhard: Del ser al hacer. Los orígenes de la biología del conocer, J.C. Sáez, Santiago, 2004.

Maturana, Humberto: Transformación en la convivencia, Dolmen Ediciones, Santiago, 2002.

MEJÍA, Julio: "Colonialidad y des/colonialidad en América Latina. Elementos teóricos", Aníbal Quijano: Des/colonialidad y bien vivir. Un nuevo debate en América Latina, Editorial URP, Lima, 2014.

MEJíA, Julio: Sociedad y conocimiento. Los desafíos de la sociología latinoamericana, UNMSM|Facultad de Ciencias Sociales, Lima, 2009.

MIGNOLO, Walter: "Desobediencia epistémica y descolonización de las ciencias sociales", Rodrigo Cordero (Editor): Formas de comprender el presente, Ediciones Universidad Diego Portal, Santiago, 2012.

MIGNOLO, Walter:"Hacia la cartografía de un nuevo mundo: pensamiento descolonial y desoccidentalización (un diálogo con Walter Mignolo). Entrevista realizada por Francisco Carballo", Otros Logos. Revista de Estudios Críticos, №3, Universidad Nacional de Camahue, 2012, pp. 263-264.

MoRIN, Edgar: El método V. La humanidad de la humanidad. La identidad humana, Cátedra, Madrid, 2003.

MORIN, Edgar: A favor y en contra de Marx, Nueva Visión, Buenos Aires, 2010.

MoRAÑA, Mabel: Inscripciones críticas. Ensayos sobre cultura latinoamericana, Editorial Cuarto Propio, Santiago, 2014, Cap. 7.

ORTIZ, Carolina: "Felipe Guaman Poma de Ayala, Clorinda Matto de Turner, Trinidad Henríquez y la teoría crítica -sus legados a la teoría social contemporánea-", Yuyaykusun, № 2, Departamento de Humanidades, Universidad Ricardo Palma, Lima, 2009, pp. 263-284.

Piedrahita Echandía, Claudia; Díaz, Álvaro y Vommaro, Pablo (Compiladores): Pensamientos críticos contemporáneos: Análisis desde Latinoamérica, Universidad Distrital Francisco José de Caldas - CLACSO, Bogotá, 2015.

PIKETTY, Thomas: El capital del siglo XXI, FCE, México, 2015.

PIKETTY, Thomas: "Utilizando una obra de Balzac.'¿Triunfar hoy? 0 eres un genio o un corrupto': Piketty explica el siglo XXI", El Confidencial, 29 de abril 2014, http://www.elconfidencial. com/alma-corazon-vida/2014-04-29/triunfar-hoy-o-eres-un-genio-o-un- corruptoel-guru-de-moda-explica-el-futuro_122640/

QUIJANO, Aníbal: "Presentación. Un nuevo debate latinoamericano”, Des/colonialidad y bien vivir. Un nuevo debate en América Latina, Fondo Editorial URP, Lima, 2014.

QUIJANO, Aníbal: "Bien vivir: entre el "desarrollo" y la des/colonialidad del poder", Cuestiones y horizontes. De la dependencia histórico-estructural a la colonialidad/descolonialidad del poder, CLACSO, Buenos Aires, 2014.

QUIJANO, Aníbal: “América Latina en la Economía mundial”, CLACSO, Buenos Aires, 2014.

QUIJANO, Aníbal: "El bicentenario de una paradoja histórica”, Tradición, № 11, Universidad Ricardo Palma, Lima, 2011, pp. 150-156.

QuIJAnO, Aníbal: "Prólogo", José Carlos Mariátegui. Textos Básicos, F. C. E., Lima, 1991, p. IX. 
QuiJAno, Aníbal: "Lo cholo y el conflicto cultural en el Perú", Dominación y cultura. Lo cholo y el conflicto cultural en el Perú, Mosca Azul Editores, Lima, 1980, [1964].

QUIJANO, Aníbal: “Dominación y cultura (Notas sobre el problema de la participación cultural)", Dominación y cultura. Lo cholo y el conflicto cultural en el Perú, Mosca Azul Editores, Lima, 1980, [1971].

QUIJANO, Aníbal: Modernidad, identidad y utopía en América Latina, Sociedad y Política Ediciones, Lima, 1988.

REYNA, Carlos: Apogeo y decadencia de los estudios culturales. Una visión antropológica. Gedisa, Barcelona, 2000;

SÁNCHEZ PARGA, José: Una 'Devastación de la inteligencia.' Crisis y crítica de las ciencias sociales. AbyaYala, 2007, Quito.

THERBORN, Göran:"Después de la dialéctica la teoría social radical en un mundo poscomunista", New Left Review $\mathrm{N}^{\circ}$ 43. Marzo/abril, 2007, pp. 59-106.

VerGARA, Alberto: Ciudadanos sin República. ¿Cómo sobrevivir en la jungla política peruana, Planeta, Lima, 2013.

WALSH, Catherine (edit.): Estudios culturales latinoamericanos. Universidad Andina Simón Bolívar / Abya-Yala, Quito, 2003.

WALLERSTEIN, Immanuel:Capitalismo histórico y movimientos antistémicos. Un análisis del sistema-mundo, Akal, Madrid, 2004.

WALLERSTEIN, Immanuel: Universalismo Europeo. El discurso del poder, Siglo XXI Editores, Madrid, 2007. WALlERSTEIN, Immanuel: Impensar las ciencias sociales, Siglo XXI - UNAM, México, 1999.

WEBER, Max: El político y el científico, Alianza, Madrid, 1997. 